\title{
SECTION 9: OPTIONAL SAMPLES
}

\subsection{INTRODUCTION}

After the first and main phase of FIRI, which focused on routinely measured materials, an optional series of samples were also made available to participating laboratories. This second list included archaeological samples, mammoth tusks, and modern cellulose. Not all samples were available in sufficient quantity for radiometric measurement (in particular, the mammoth tusks). The samples are briefly described in Table 9.1 below.

Table 9.1 Description of optional samples

\begin{tabular}{ll}
\hline Sample & Description \\
\hline $\mathrm{K}$ & Cambridge cellulose \\
$\mathrm{L}$ & Dogee Barrow wood \\
$\mathrm{M}$ & whole peat \\
$\mathrm{N}$ & mammoth tusk \\
$\mathrm{O}$ & mammoth tusk \\
$\mathrm{P}$ & mammoth tusk \\
\hline
\end{tabular}

\subsection{SAMPLE DESCRIPTION}

For Sample K, the dendro-age is known. Sample M had been previously pretested and came from the same site as Sample E. The Dogee Barrow site had been extensively dated, as had the mammoth tusks.

Sample K came from a tree that was planted around AD 1722 and material corresponding to the period AD 1820-1880 (a relatively flat area on the calibration curve) provided the sample. It has been homogeneity tested (approximately $98 \mathrm{pMC}$ ).

The 3 mammoth tusks had been previously dated with results for Sample N (T-13440, 28,075 \pm 255 and LU-3983, 29,170 \pm 340 ), Sample O (Lu-4170, age 39,320 \pm 960), and Sample P (Lu-1967, age $12,820 \pm 60)$.

Sample L came from the burial mound of Dogee Barrow, grave 8 (the Tuva king barrows). The approximate age was 2300-2400 BP.

Only a limited number of laboratories measured the optional samples and the summary statistics are shown below (the full table of results is given in Appendix 2).

Table 9.2 Descriptive statistics for the optional samples (in yr BP)

\begin{tabular}{lrcrrrrrr}
\hline Sample & N & Mean & Median & StDev & Minimum & Maximum & Q1 & \multicolumn{1}{c}{ Q3 } \\
\hline K & 6 & 126.2 & 76.5 & 104 & 40 & 310 & 58 & 220 \\
L & 10 & 2505 & 2500 & 123 & 2386 & 2790 & 2406 & 2548 \\
M & 15 & 11,139 & 11,120 & 191 & 10,710 & 11,413 & 11,070 & 11,300 \\
N & 5 & 28,100 & 28,574 & 1177 & 26,000 & 28,746 & 27,265 & 28,698 \\
O & 5 & 37,815 & 37,980 & 2143 & 34,700 & 40,504 & 35,910 & 39,639 \\
P & 5 & 12,558 & 12,600 & 151 & 12,300 & 12,696 & 12,443 & 12,653 \\
\hline
\end{tabular}


Table 9.3 Descriptive statistics for the optional samples (in pMC)

\begin{tabular}{lrccccccc}
\hline Sample & N & Mean & Median & StDev & Minimum & Maximum & Q1 & Q3 \\
\hline K & 7 & 98.737 & 99.1 & 1.407 & 96.2 & 100.482 & 97.7 & 99.727 \\
L & 8 & 73.514 & 73.644 & 0.752 & 72.333 & 74.29 & 72.918 & 74.203 \\
M & 11 & 24.849 & 24.79 & 0.603 & 24.14 & 26.3 & 24.4 & 25.16 \\
N & 5 & 3.048 & 2.85 & 0.477 & 2.79 & 3.9 & 2.81 & 3.385 \\
O & 5 & 0.922 & 0.88 & 0.243 & 0.65 & 1.3 & 0.725 & 1.14 \\
P & 5 & 20.94 & 20.84 & 0.385 & 20.59 & 21.6 & 20.695 & 21.235 \\
\hline
\end{tabular}

\subsubsection{Comments}

We can see that the results are in general agreement with the previous dating results and the knownage dendro date. No further analysis of the results for these materials has been undertaken. Given the small number of results, consensus values have not been calculated, but there still remains a sufficient archive to allow laboratories to measure these materials as part of their in-house QA procedures. 